\title{
Valuing Satellite Systems to Support Fishing in a Dynamic Competitive Model*
}

\author{
Fabrice Collard ${ }^{\dagger}$ Carole Haritchabalet ${ }^{\ddagger}$
}

April 2006

\begin{abstract}
This paper investigates the technology adoption decision of a new satellite system aimed at locating tuna shoals. We propose a dynamic imperfect competition model with vertical differentiation in which each firm acts as a Cournot oligopolist and takes the evolution of the natural resources into account. We find that high quality firms value more the technology than low quality firms. A direct implication of this result is that the market value of the new technology can be maximized while letting all firms adopt the new technology provided the adoption cost differs across firms. If not, it is profitable to serve only the highest quality firms. We show that individual quotas can be used to increase the value that both firms attach to the technology when high quality firms are restricted in their production levels.
\end{abstract}

Key Words: Technology adoption, Dynamic Cournot competition, Fisheries.

JEL Class.: L13, Q22, Q55

${ }^{*}$ We would like to acknowledge the financial support of CNES, contract 4700015608/SIE491. We are thankful to Michel Moreaux and Alain Oustry as well as the participants to the CNES workshop for very valuable comments.

${ }^{\dagger}$ CNRS-GREMAQ, Manufacture des Tabacs, bât. F, 21 allée de Brienne, 31000 Toulouse, France. Tel: (33-5) 61-12-85-42, Fax: (33- 5) 61-22-55-63, email: fabrice.collard@gremaq.univ-tlse1.fr, Homepage: http://fabcol.free.fr

${ }^{\ddagger}$ GREMAQ, Manufacture des Tabacs, bât. F, 21 allée de Brienne, 31000 Toulouse, France. Tel: (33-5) 61-12-85-60, Fax: (33- 5) 61-22-55-63, email: carole.haritchabalet@univ-tlse1.fr 


\section{Introduction}

The production in the fishery industry is largely contingent on the migration of fish populations. One of the prominent technological aspect of the fishing activity is therefore the ability to locate shoals. New satellite systems can now be used to facilitate this task, provided firms are willing to pay the investment cost. The adoption of such a technology ought to allow firms to reduce their production cost which modifies competition between them. This paper investigates the incentives for investing in a satellite system to support fishing.

We consider an imperfect competition model in which each firm acts as a Cournot oligopolist in a dynamic framework and takes the policy of the other firm as given. One important aspect of the satellite system technology adoption we want to emphasize is that it critically depends on the characteristics of the firms. In particular, equilibrium prices of fish differ across fishing firms of different types. To capture this idea, we analyse competition in a vertical product differentiation model. In order to keep the model tractable, and without loss of generality, we assume that only two categories of firms operate in the market. The two firms are assumed to play a two-stage game. In the first stage, each fishing firm decides wether or not to adopt the satellite system technology. Adopting the technology yields a decrease in the marginal cost but triggers an adoption cost. In the second stage, dynamic competition takes place. Production plans decided in the second stage of the game obviously affect the size of the fish population. Firms acknowledge this effect and therefore take it into account when deciding their production plans. But, more importantly, since the technology adoption decisions modifies firms' cost and thus competition, the first stage game also affects the future size of the fish population.

Our analysis is first concerned with the impact of cost reduction on firms' competition and focuses on pure profit motive for the adoption of the technology leaving aside its implications for the dynamics of fish population. We derive clear cut decisions regarding technology adoption for a given stock of fish. The market equilibrium is important to understand the profitability of the technology. The higher the output of a given firm, the larger is the total gain from a reduction in unit costs of production. First-order conditions for profit maximization are thus not sufficient to determine the incentives for innovation. A market analysis has to be undertaken to understand the value that each firm attaches to this cost reducing technology. Our results suggest that differences in firms' initial costs or in firms' product quality are key determinants of incentives to adopt the technology. Furthermore, we show that the marginal return on the technology adoption is increasing. This implies that each category of firms attaches more value to the new technology if the other type of fishing firms does not possess it. We then show how to derive the market value of the satellite support strategy from equilibrium profits and the cost that firms pay to be equipped with the technology. 
We then extend the analysis to a dynamic setting in order to take the impact of the new technology on the level of the stock of fish into account. The economics of natural resources and fishing has been extensively studied. The pioneering work of Clark [1971], Clark and Munro [1975], and Levhari and Mirman [1980] is important to study the economics implications of fishing for the population of fish. They study various aspect aspects of optimal fishing policies and their effect on the size of possible depletion of the fish population. We focus on the relation between the adoption of the new technology, the evolution of the stock and market competition. We also derive the social value of the technology and study which category of fishing firms should adopt the cost reducing technology. We then assess the impact of how individual quotas modify on the market valuation of the satellite system support technology.

The model cannot be solved analytically. We therefore rely on a numerical approach which triggers a calibration of the model. The results are derived for for the northern bluefin tuna and the two categories of firms that we consider are long line and purse seine firms (long line firms producing the better quality fish). We compute the market value of the satellite system from the market harvest equilibrium. In our vertically differentiated model, we obtain that high quality firms produce less whereas low quality firms produce more than the socially optimal production level. Therefore, high quality firms should be the first category of firms encouraged in the adoption of the technology. If the cost of producing the technology is lower than its market value, we obtain that all categories of firms should be equipped with the technology. We show that individual quotas can be used to increase the value that both firms attach to the technology when high quality firms are restricted in their production levels. If quotas only concern low quality firms, the market value of the cost reduction technology decreases.

Section 2 presents a static model of technology adoption in which two types of firms compete on the market but do not internalize the future effect of their decisions on the stock of fish. Section 3 extends the preceding analysis to a dynamic setting where the stock of tuna evolves over time according to biological constraints and fishing activities. Section 4 discusses the calibration of the model. Section 5 presents the numerical results for the dynamic version of the model. In particular it discusses cost reducing technology adoption both in equilibrium and at the social optimum. We then introduce quotas in the model to shed light on their role in the regulation of the market.

\section{A static model}

We consider an economy with two types of fishing firms that exploit a single constant stock of fish, $x$. The fishing industry consists of $n_{1} \geqslant 1$ (resp. $n_{2} \geqslant 1$ ) fishing firms of type 1 (resp. type 2 ). We consider a vertically differentiated industry where the quality of fish is specific to the 
type of firm and yields a specific market value.

\subsection{The Players}

Consumers: We assume that consumers preferences are represented by the following utility function

$$
U= \begin{cases}v u-p & \text { when Tuna consumption is positive } \\ 0 & \text { otherwise }\end{cases}
$$

where $p$ and $u$ respectively denote the price and the quality of fish. Type 1 firms (type 2 firms) are assumed to produce fish with quality $u_{1}\left(u_{2}\right)$, with $u_{1} \geqslant u_{2}$. Hereafter, we will consider the quality levels as fixed. $v$ is a taste parameter that is specific to each consumer. $v$ is uniformly distributed over the support $[\underline{v}, \bar{v}]$. The higher the quality of the good, the higher the utility $U$ reached by the consumers for any given price $p$. However, consumer with a higher $v$ will be willing to pay more for a higher quality fish. Let us define $v_{12}$ as the level of the taste parameter such that the consumer is indifferent between buying good 1 or good 2 . Then, $v_{12}$ is given by

$$
v_{12}=\frac{p_{1}-p_{2}}{u_{1}-u_{2}}
$$

Likewise, we define $v_{\varnothing 2}$ as the value of the taste parameter such that the consumer indifferent between buying type 2 fish and not buying fish at all. $v_{\varnothing 2}$ is given by

$$
v_{\varnothing 2}=\frac{p_{2}}{u_{2}} .
$$

Given these assumptions, the system of inverse demand functions is given by

$$
\begin{aligned}
& p_{1}=\bar{v} u_{1}-u_{1} Q_{1}-u_{2} Q_{2} \\
& p_{2}=\bar{v} u_{2}-u_{2} Q_{1}-u_{2} Q_{2}
\end{aligned}
$$

where $p_{i}$ is the price paid to firm $i$ when the aggregate production of type $i$ firms is $Q_{i}$ and the aggregate production of type $j$ firms is $Q_{j}$.

Fishing Industry: Let $q_{i j}$ be the quantity harvested by firm $j$ with type $i$. The aggregate harvest $Q$ is thus given by

$$
Q=\sum_{j=1}^{n_{1}} q_{1 j}+\sum_{j=1}^{n_{2}} q_{2 j}=Q_{1}+Q_{2} .
$$

The cost function of type $i$ firm for harvesting a quantity $h$ when the level of the stock of fish, $x$, is present is given by

$$
c_{i}(q, x)=c_{i} q x^{\alpha_{i}}
$$


This cost function is derived from a Cobb Douglas production function with fishing effort and fish biomass as production inputs of the form

$$
q=\theta_{i} e x^{-\alpha_{i}}
$$

where $e$ is the effort of the firm. $\theta_{i}$ is productivity term that measures the catchability per unit of effort. Finally, $-\alpha_{i}$ is the catch stock elasticity. This latter effect aims at capturing the fact that it is easier and less expensive to catch fish when the population of fish is large. The parameter $c_{i}$ in the cost function represents the harvest ability of each type of firm.

Given these specifications, the instantaneous profit function of a type $i$ firm is written as

$$
\pi_{i}(q, x)=p_{i}(Q) q-c_{i} q x^{\alpha_{i}}
$$

We assume that before the market opens, each firm can invest, $T_{i}$, in a satellite system to support fishing by enhancing the ability of firm $i$ to detect shoals. When implemented, the technology yields a cost reduction, which takes the form of a cut in the parameter $c_{i}$, which is then reduced by $\delta_{i}$ where $0<\delta_{i}<c_{i}$. The investment decision of the firm is a discrete decision - to invest or not - denoted by $\mu_{i}$ where $\mu_{i}=\left\{0, \delta_{i}\right\}$. The value of the firm is then defined as the difference between its instantaneous variable profit and the cost of the technology, $T_{i}$, when implemented

$$
V_{i}\left(\mu_{i}, x\right)=\pi_{i}(q, x)-T_{i} \mathbb{1}_{\left[\mu_{i}=\delta_{i}\right]}
$$

where $\mathbb{I}_{[\mu=\delta]}=1$ if $\mu=\delta, 0$ otherwise.

The behavior of type $i$ firm is then determined by solving a two-stage game. In the fist stage of the game, each firm decides whether or not to invest in the cost reduction technology. In the second stage, all firms compete in the level of harvest. We look for a symmetric Nash equilibrium in which each firm with the same type has the same technology adoption strategy and produces the same level of harvest. The game is solved by backward induction. We first solve the competition between firms as a function of the firms' decisions to invest in the cost reduction technology. We then analyze the decision to invest in the cost reduction technology as a function of the technology cost.

\subsection{Market Competition}

We first present the Cournot equilibrium in which each firm decides on its harvesting level so as to maximize its profit given the quantity harvested by its competitors. Therefore, the harvesting 
decision of firm $j$ with type 1 solves the program:

$$
\begin{gathered}
\max _{q_{1 j}} \pi_{1 j} \equiv p_{1}(Q) q_{1 j}-\left(c_{1}-\mu_{1 j}\right) q_{1 j} x^{\alpha_{1}} \\
\text { s.t. } p_{1}=\bar{v} u_{1}-u_{1} \sum_{j=1}^{n_{1}} q_{1 j}-u_{2} \sum_{j=1}^{n_{2}} q_{2 j}
\end{gathered}
$$

where $\mu_{1 j} \in\{0 ; \delta\}$ is known from the first stage of the game.

The first order condition is given by

$$
\frac{\partial \pi_{1 j}}{\partial q_{1 j}}=\bar{v} u_{1}-u_{1} q_{1 j}-u_{1} \sum_{j=1}^{n_{1}} q_{1 j}-u_{2} \sum_{j=1}^{n_{2}} q_{2 j}-\left(c_{1}-\mu_{1}\right) x^{\alpha_{1}}=0
$$

Likewise, Firm $j$ with type 2 chooses a quantity of harvest $q_{2 j}$ such that it solves

$$
\begin{aligned}
& \max _{q_{2 j}} \pi_{2 j} \equiv p_{2}(Q) q_{2 j}-\left(c_{2}-\mu_{2 j}\right) q_{2 j} x^{\alpha_{2}} \\
& \text { s.t. } p_{2}=\bar{v} u_{2}-u_{2} \sum_{j=1}^{n_{1}} q_{1 j}-u_{2} \sum_{j=1}^{n_{2}} q_{2 j}
\end{aligned}
$$

and the first order condition is given by ${ }^{1}$

$$
\frac{\partial \pi_{2 j}}{\partial q_{2 j}}=\bar{v} u_{2}-u_{2} q_{2 j}-u_{2} \sum_{j=1}^{n_{2}} q_{2 j}-u_{2} \sum_{j=1}^{n_{1}} q_{1 j}-\left(c_{2}-\mu_{2}\right) x^{\alpha_{2}}=0
$$

In a symmetric equilibrium, we have $q_{1 i}=q_{1 j}=q_{1}^{\star}$ and $q_{2 i}=q_{2 j}=q_{2}^{\star}$ for all $i, j$. Then, we have $Q_{1}=\sum_{j=1}^{n_{1}} q_{1 j}=n_{1} q_{1}^{\star}$ and $Q_{2}=\sum_{j=1}^{n_{2}} q_{2 j}=n_{2} q_{2}^{\star}$. Substituting these values into (4)-(5) yields

$$
\begin{aligned}
q_{1}^{\star} & =\frac{\bar{v}\left(\left(n_{2}+1\right) u_{1}-n_{2} u_{2}\right)-\left(n_{2}+1\right)\left(c_{1}-\mu_{1}\right) x^{\alpha_{1}}+n_{2}\left(c_{2}-\mu_{2}\right) x^{\alpha_{2}}}{u_{1}\left(n_{1}+1\right)\left(n_{2}+1\right)-u_{2} n_{1} n_{2}} \\
q_{2}^{\star} & =\frac{\bar{v} u_{1}-\left(n_{1}+1\right)\left(u_{1} / u_{2}\right)\left(c_{2}-\mu_{2}\right) x^{\alpha_{2}}+n_{1}\left(c_{1}-\mu_{1}\right) x^{\alpha_{1}}}{u_{1}\left(n_{1}+1\right)\left(n_{2}+1\right)-u_{2} n_{1} n_{2}}
\end{aligned}
$$

As expected, a cost reduction for firm $i\left(d c_{i}<0\right)$ increases $q_{i}^{\star}$ as it just reflects an increase in the productivity of this firm. This cost reduction enables firm $i$ to capture a larger share of the market such that firm $j$ experiences a drop in production. $q_{j}^{\star}$ decreases.

Aggregate harvest is simply given by

$$
Q^{\star}=\frac{n_{1} n_{2} \bar{v}\left(u_{1}-u_{2}\right)-n_{1}\left(c_{1}-\mu_{1}\right) x^{\alpha_{1}}+\left(n_{1} n_{2}\left(u_{1}-u_{2}\right) / u_{2}-n_{2} u_{1} / u_{2}\right)\left(c_{2}-\mu_{2}\right) x^{\alpha_{2}}}{u_{1}\left(n_{1}+1\right)\left(n_{2}+1\right)-u_{2} n_{1} n_{2}}
$$

Since technology adoption is dictated by the firms' payoffs in the first stage of the game, we now characterize the profit attained by each firm in the symmetric equilibrium. It should be

\footnotetext{
${ }^{1}$ It can be easily verified that $\frac{\partial^{2} \pi_{i j}}{\partial q_{i j}^{2}}<0 \forall i$ and $j$.
} 
clear to the reader that firms' payoffs depend upon both firms' costs and thus on the first period decision to adopt or not the cost reduction technology. Let us denote by $\pi_{i}\left(\mu_{1}, \mu_{2}\right)$ the profit attained by a type $i=1,2$ firm in a symmetric equilibrium given the first period decisions of each type of firm $\mu_{1}$ and $\mu_{2}$. We have $e^{2}$

$$
\begin{aligned}
\pi_{1}^{\star}\left(\mu_{1}, \mu_{2}\right) & =\frac{u_{1}\left(\bar{v}\left(\left(n_{2}+1\right) u_{1}-n_{2} u_{2}\right)-\left(n_{2}+1\right)\left(c_{1}-\mu_{1}\right) x^{\alpha_{1}}+n_{2}\left(c_{2}-\mu_{2}\right) x^{\alpha_{2}}\right)^{2}}{\left(u_{1}\left(n_{1}+1\right)\left(n_{2}+1\right)-u_{2} n_{1} n_{2}\right)^{2}} \\
\pi_{2}^{\star}\left(\mu_{1}, \mu_{2}\right) & =\frac{u_{2}\left(\bar{v} u_{1}-\left(n_{1}+1\right)\left(u_{1} / u_{2}\right)\left(c_{2}-\mu_{2}\right) x^{\alpha_{2}}+n_{1}\left(c_{1}-\mu_{1}\right) x^{\alpha_{1}}\right)^{2}}{\left(u 1\left(n_{1}+1\right)\left(n_{2}+1\right)-u 2 n_{1} n_{2}\right)^{2}}
\end{aligned}
$$

It can be readily checked, using the enveloppe theorem, that an increase in $c_{i}$ (resp. $c_{j}$ ) decreases (resp. increases) type $i$ firms' profits.

\subsection{Technology Adoption}

We now consider the first period stage in which each type of firm independently chooses whether to adopt the new technology.

Strategies and payoffs may be summarized by the following gain matrix where the strategy of a firm of type 1 is indicated in each row, while firms of type 2 refer to each column. $A_{i}$ (resp.

\begin{tabular}{|c|c|c|}
\hline & $\mathrm{A}_{2}$ & $\mathrm{~A}_{2}$ \\
\hline $\mathrm{A}_{1}$ & $\left(\pi_{1}^{\star}\left(\delta_{1}, \delta_{2}\right)-T_{1}, \pi_{2}^{\star}\left(\delta_{1}, \delta_{2}\right)-T_{2}\right)$ & $\left(\pi_{1}^{\star}\left(\delta_{1}, 0\right)-T_{1}, \pi_{2}^{\star}\left(\delta_{1}, 0\right)\right)$ \\
\hline$X_{1}$ & $\left(\pi_{1}^{\star}\left(0, \delta_{2}\right), \pi_{2}^{\star}\left(0, \delta_{2}\right)-T_{2}\right)$ & $\left(\pi_{1}^{\star}(0,0), \pi_{2}^{\star}(0,0)\right)$ \\
\hline
\end{tabular}
$A_{i}$ ) indicates that type $i$ firm adopts (resp. does not adopt) the new technology.

The Nash equilibrium of the game then determines the choice of the two types of firm.

Let us first characterize type $i$ firm best response as a function of parameter values. This best response function depends on the decision of type $j$ firms.

If type 1 firms do not adopt the cost reduction technology then it is optimal for type 2 firms to adopt the technology if :

$$
\Delta_{1}(0) \equiv \pi_{1}^{\star}\left(\delta_{1}, 0\right)-\pi_{1}^{\star}(0,0) \geq T_{1}
$$

If type 1 firms adopt the cost reduction technology then it is optimal for type 2 firms to adopt the technology if :

$$
\Delta_{1}\left(\delta_{2}\right)=\pi_{1}^{\star}\left(\delta_{1}, \delta_{2}\right)-\pi_{1}^{\star}\left(0, \delta_{2}\right) \geq T_{1}
$$

Similarly, we can define $\Delta_{2}\left(\delta_{1}\right)$ (resp. $\Delta_{2}(0)$ ) as the increase in the variable profit of type 2 firm if it adopts the technology when type 1 firms has adopted (resp. has not adopted) the new technology.

\footnotetext{
${ }^{2}$ In the sequel, we denote $\pi_{i}^{\star}\left(\mu_{1}=\delta_{1}, \mu_{2}=\delta_{2}\right)$ by $\pi_{i}^{\star}\left(\delta_{1}, \delta_{2}\right)$.
} 
If for a given type of firm $\Delta_{i}\left(\delta_{j}\right)$ and $\Delta_{i}(0)$ are greater (resp. lower) than the technology cost $T_{i}$, then adopting (resp. not adopting) the new technology is a dominant strategy for the firm. Else, the choice of the firm is driven by the behavior of the other firm. The following result helps us to understand the incentives to adopt the new technology.

Lemma $1 \Delta_{i}$ is a decreasing (resp. increasing) function of $c_{i}$ (resp. $c_{j}$ ).

As in Bester and Petrakis [1994], the marginal return on investment in the cost reduction technology is increasing. It is therefore more profitable for a firm to invest in the cost reducing technology when its production cost is low. Part ii) of Proposition 1 indicates that a firm has more incentives to adopt the new technology when the other firm has a high production cost i.e. when the other firm is not equipped with the new technology $\left(\Delta_{i}\left(\delta_{j}\right)<\Delta_{i}(0)\right)$. In other words, the technology is less profitable when the other firm also reduces its cost. These cost reduction strategies are strategic substitutes.

The equilibrium of the game then depends on the relation between $\Delta_{i}\left(\mu_{j}\right)$ and $\Delta_{j}\left(\mu_{i}\right)\left(\mu_{i}=\right.$ $\left.\left\{0, \delta_{i}\right\}\right)$ and is specific to industry parameters. The difference between firm costs and the number of each type of firms gives the equilibrium.

The next proposition summarizes all possible cases and indicates in each case the equilibrium adoption decision of each firm and their willingness to pay for the technology $(w)$.

Proposition 1 The possible equilibria of the game are given by

1. When $\Delta_{i}\left(\mu_{j}\right) \geqslant T_{i} \forall i$ and $\forall \mu_{j}$, the equilibrium is $\left(A_{i}, A_{j}\right)$ and the willingness to pay for the cost reducing technology is $w_{i}=\Delta_{i}\left(\delta_{j}\right) \forall i$.

2. When $\Delta_{i}\left(\mu_{j}\right)<T_{i} \forall i$ and $\forall \mu_{j}$, the equilibrium is $\left(A_{i}, A_{j}\right)$ and the willingness to pay for the cost reducing technology is $w_{i}=0 \forall i$.

3. When $\Delta_{i}\left(\delta_{j}\right)<T_{i}, \Delta_{i}(0) \geqslant T_{i}$ and $\Delta_{j}\left(\mu_{i}\right) \geqslant T_{j} \forall i$ and $\forall \mu_{i}$, the equilibrium is $\left(A_{i}, A_{j}\right)$ and the willingness to pay for the cost reducing technology are $w_{i}=0$ and $w_{j}=\Delta_{j}(0)$.

4. When $\Delta_{i}\left(\delta_{j}\right)<T_{i} \forall i, \Delta_{i}(0)<T_{i}$ and $\Delta_{j}(0) \geqslant T_{j}$, the equilibrium is $\left(A_{i}, A_{j}\right)$ and the willingness to pay for the cost reducing technology are $w_{i}=0 w_{j}=\Delta_{j}(0)$.

5. When $\Delta_{i}\left(\delta_{j}\right)<T_{i} \forall i$ and $\Delta_{i}(0) \geqslant T_{i} \forall i$, there are two equilibria

i) $\left(A_{i}, A_{j}\right)$ with willingness to pay for the cost reducing technology $w_{i}=0$ and $w_{j}=$ $\Delta_{j}(0)$

ii) $\left(A_{i}, A_{j}\right)$ with willingness to pay for the cost reducing technology $w_{i}=\Delta_{i}(0)$ and $w_{j}=0$. 
In case 1, adopting the new technology is a dominant strategy for both firms and we observe a joint adoption. In this case, both type $i$ firms are willing to pay $\Delta_{i}\left(\delta_{j}\right)$ which represents the increases in firm $i$ profit after the adoption given that firm $j$ is also equipped. Conversely, in case 2 , not adopting the new technology is a dominant strategy for both types of firm.

In case 3 and 4, adopting the new technology is a dominant strategy for type $j$ firms and type $i$ firms value positively the technology only if they invest alone. We thus obtain a unique adoption from firm $j$.

In case 5, each type of firms value positively the technology only if they invest alone in the new technology. As a consequence, and because marginal returns in the technology increases with the competitor costs, there is a coordination problem between the two types of firms and the game admits two equilibria.

An attractive feature of this model is that it delivers clear cut decisions regarding technology adoption for a given stock of fish. However, the model implies myopic decision from the firms as it does not take into account the impact of the new technology on the level of the stock. This is clearly a shortcoming of this approach and it calls for an explicitly dynamic model that let firms take the impact of the new technology on the reproduction rate of the stock of fish. The next section deals with this problem and proposes a dynamic model in which the stock of tuna evolves over time and depends on harvesting behavior.

\section{A Dynamic Fishing Model}

This section develops a model in the lines of the model of the previous section. we consider a two-stage game where, in the first stage, each firm decides whether or not to invest in the cost reduction technology and, in the second stage, all firms engage in a dynamic competition in the level of harvest. We however depart from the previous modelling in that we allow the stock of fish to evolve over time and let agents take the impact of their decisions on the future stock of fish into account. The model is then explicitly dynamic.

\subsection{The Evolution of the Stock of Fish}

We now consider that the stock of fish, $x$, is a dynamic variable. The resource depends on its natural, or biological, growth function and on the harvesting activity. More precisely, denoting by $x_{t}$ the stock of fish at date $t$, the stock in period $t+1$ is the difference between the biological evolution of the stock and the harvest

$$
x_{t+1}=F\left(x_{t}\right)-Q_{t}
$$


$Q_{t}$ denotes the aggregate production of the fishery industry in the economy. It therefore accounts for the harvesting activity of firms and exerts a negative effect on the stock of fish. $F\left(x_{t}\right)$ corresponds to the natural evolution of the stock of fish, and hence accounts for the biological component. This latter component has been extensively studied in the biological literature (See e.g. Clark and Conrad [1987]). In the sequel, $F(\cdot)$ is borrowed from this literature and takes the form

$$
F\left(x_{t}\right)=r x_{t}\left(1-\frac{x_{t}}{k}\right)+x_{t}
$$

where $r$ is the intrinsic growth rate of the resource stock and $k$ denotes the environmental carrying capacity. Note that the knowledge of the current period stock, $x_{t}$ and the production level suffice to fully characterize the next period stock of tuna. $x_{t}$ is then a predetermined variable. Hence, the dynamics of the shock of fish are described by the following law of motion

$$
x_{t+1}=r x_{t}\left(1-\frac{x_{t}}{k}\right)+x_{t}-Q_{t}
$$

\subsection{The Nash-Cournot Equilibrium}

We first solve the dynamic competition between firms to compute the present value of each firm profit. We then perform the same exercise as in the static problem: we consider the choice of each firm to adopt the cost reduction technology through a matrix that indicates the value of firms' profits according to the strategy of each type of firm.

In a dynamic setting the firm takes into account the impact of its action on its current profit but also on the discounted flow of profits it will get in the future. Therefore, the objective function of a type $i$ firm is given by

$$
\Pi\left(\mu_{i}\right)=\sum_{t=1}^{\infty} \beta^{t-1}\left(p_{i}\left(Q_{t}\right) q_{i t}-\left(c_{i}-\mu_{i}\right) q_{i t} x_{t}^{\alpha_{i}}\right)
$$

where $\beta \in(0,1)$ is the discount factor of the firm. The optimal production plan of the firm - the sequence $\left\{q_{i t}\right\}_{t=1}^{\infty}$ of harvest levels - maximizes 12 subject to the demand functions it faces, the biological constraint, positivity constraints on harvests and the stock of fish, and 
taken the harvest of type $j$ firms as given. Therefore, the program of the firm writes

$$
\begin{array}{ll}
\max _{q_{i j t}} \Pi\left(\mu_{i}\right)=\sum_{t=1}^{\infty} \beta^{t-1}\left(p_{i}\left(Q_{t}\right) q_{i j t}-\left(c_{i}-\mu_{i}\right) q_{i j t} x_{t}^{\alpha_{i}}\right) \\
\text { s.t. } p_{1}\left(Q_{t}\right)=\bar{v} u_{1}-u_{1} \sum_{j=1}^{n_{1}} q_{1 j t}-u_{2} \sum_{j=1}^{n_{2}} q_{2 j t} \\
p_{2}\left(Q_{t}\right)=\bar{v} u_{2}-u_{2} \sum_{j=1}^{n_{1}} q_{1 j t}-u_{2} \sum_{j=1}^{n_{2}} q_{2 j t} \\
q_{i j t} \geqslant 0 \\
q_{i j t} \leqslant k_{i} \\
x_{t+1}=r x_{t}\left(1-\frac{x_{t}}{k}\right)+x_{t}-\left(\sum_{j=1}^{n_{1}} q_{1 j t}+\sum_{j=1}^{n_{2}} q_{2 j t}\right) \\
x_{t+1} \geqslant 0
\end{array}
$$

We thus consider that fishing firms are rational and take the appropriate notice of all variables and relationships affecting their profit functions including the resource growth constraint and each other's fishing activity 3 Note that the behavior of competitors is constrained by the fact that they have to keep next period stock of fish positive in order for their activity to be dynamically sustainable. The price at time $t, p_{i}\left(Q_{t}\right)$, is determined by total harvest $Q_{t}$. Though each firm will manipulate the price schedule via the quantities it send to the market, each firm takes the price vector as given. These prices may be thought of as determined in future markets under conditions of perfect foresight and are given by the inverse demand function as determined in section 2.1. Also note that, through equation (17), we include the possibility that the industry is regulated by means of individual catch quotas. As a consequence, firms may be constrained in their harvest level.

The set of all first order conditions for this problem is reported in Appendix A. Although we will not discuss all of them in details, some - evaluated in a symmetric equilibrium — actually call for some comments

$$
\begin{array}{lc}
\lambda_{1 t} & =v u_{1}-u_{1}\left(1+n_{1}\right) q_{1 t}-n_{2} u_{2} q_{2 t}-\left(c_{1}-\mu_{1}\right) x_{t}^{\alpha_{1}} \\
\lambda_{2 t} & =v u_{2}-u_{2} n_{1} q_{1 t}-\left(1+n_{2}\right) u_{2} q_{2 t}-\left(c_{2}-\mu_{2}\right) x_{t}^{\alpha_{2}} \\
\lambda_{1 t}=\beta\left[\lambda_{1 t+1}\left(1+r\left(1-\frac{2}{k} x_{t+1}\right)\right)-\alpha_{1} q_{1 t+1}\left(c_{i}-\mu_{i}\right) x_{t+1}^{\alpha_{1}-1}\right] \\
\lambda_{2 t}=\beta\left[\lambda_{2 t+1}\left(1+r\left(1-\frac{2}{k} x_{t+1}\right)\right)-\alpha_{2} q_{2 t+1}\left(c_{i}-\mu_{i}\right) x_{t+1}^{\alpha_{2}-1}\right]
\end{array}
$$

\footnotetext{
${ }^{3}$ In the fisheries economic literature, there is some ambiguity about the firms' perception of the biomass constraint. Some studies retain the assumption that firms compete in the level of harvest and ignore the biomass growth constraint. Firms thus behave myopically. See for instance Okugushi [2003], Sandal and Steinshamn [2004] or Szidarovsky, Ilieva and Okuguchi [2002].
} 
for all $i$ and $t$ for which $q_{i t}>0, x_{t+1}>0$ and ignoring quotas. Parameter $\lambda_{i t}$ is type $i$ firms marginal valuation of an additional unit of biomass. The first two equation therefore indicate that the firm will fish tuna up to the point where the marginal net profit gain from extracting one additional tuna from the stock equates its marginal valuation. The marginal net profit gain is the sum of three components: (i) a direct effect stemming from the fact that the firm sells an additional unit, (ii) an indirect competition effect pertaining to the manipulation of the price scheme by the oligopolist and (iii) a negative marginal cost effect. The two last relations actually rule the dynamics of the marginal valuation of the stock of fish and reflect the forward looking behavior of firms. This actually rules the dynamic fishing decision. The firm can fish an additional tuna in period $t$, in which case it can obtain $\lambda_{i t}$ extra units of net profits. But it may also wait an additional period and let tuna reproduce, in which case it will be able to fish $\left(1+r\left(1-\frac{2}{k} x_{t+1}\right)\right)$ extra tunas in the next period which will both raise its net profits by $\lambda_{i, t+1}$. Beside this direct effect, by letting the fish stock renew, postponing fishing triggers a reduction in the cost that makes it more beneficial to wait an extra period. The non-arbitrage principle implies that the intertemporal allocation of the fishing activity is such that the current and the next period marginal valuation of the stock of fish equate.

Just alike in the static model, the quantity harvested by each firm is a function of the current value of the stock and the technology decision of each type of firms. Strategies and payoffs of each type of firms may be then summarized, as in the previous section, by a matrix indicating firms' values in the four possible cases: $\left(\mathrm{A}_{i}, \mathrm{~A}_{j}\right),\left(\mathrm{A}_{i}, \mathbb{X}_{i}\right),\left(\mathbb{X}_{i}, \mathrm{~A}_{i}\right)$ and $\left(\mathbb{X}_{i}, \mathbb{X}_{j}\right)$.

\subsection{The social optimum}

For comparative purposes it is interesting to investigate the dynamic properties of the social optimum. We thus define the instantaneous consumer surplus by

$$
S(Q)=\int_{v_{\varnothing 2 t}}^{v_{12 t}}\left(v u_{2}-p_{2 t}\right) d v+\int_{v_{12 t}}^{\bar{v}_{t}}\left(v u_{1}-p_{1 t}\right) d v
$$

with $v_{12 t}-v_{\varnothing 2 t}=n_{2} q_{2 t}$ and $\bar{v} t-v_{12 t}=n_{1} q_{1 t}$.

Social welfare at date $t$ is then given by

$$
W\left(Q_{t}\right)=S\left(Q_{t}\right)-C\left(Q_{t}\right)
$$

where $C\left(Q_{t}\right)$ is the total production cost.

The problem of the social planner is (i) to find the sequence of harvest that maximizes the present value of social surplus subject to the biological constraints and (i) to decide whether firms should be equipped with the new technology or not given the production cost of the 
technology $\left.\right|^{4}$ More formally, denoting $\Gamma(n)$ the total cost to equip a number of $n$ firms with the technology $5^{5}$ the problem of the social planner is

$$
\begin{aligned}
\max _{q_{1 t}, q_{2 t}, \mu_{1}, \mu_{2}} & \sum_{t=1}^{\infty} \beta^{t-1}\left(S\left(n_{1} q_{1 t}+n_{2} q_{2 t}\right)-n_{1}\left(c_{1}-\mu_{1}\right) q_{1} x^{\alpha_{1}}+n_{2}\left(c_{2}-\mu_{2}\right) q_{2} x^{\alpha_{2}}\right. \\
& \left.-\Gamma\left(n_{1} \mathbb{I}_{\left[\mu_{1}=\delta_{1}\right]}+n_{2} \mathbb{I}_{\left[\mu_{2}=\delta_{2}\right]}\right)\right) \\
\text { s.t. } & x_{t+1}=r x_{t}\left(1-\frac{x_{t}}{k}\right)+x_{t}-Q_{t} \\
& x_{t+1} \geqslant 0
\end{aligned}
$$

The problem can be decomposed in two steps and solved by backward induction. First, we determine socially optimal harvest levels as a function of productions costs. Second, given the value of social welfare associated to each costs levels, we determine the optimal equipment of each type of firms. First order conditions that determine optimal harvest levels are reported in Appendix B. Although we will not discuss all of them in details, some - evaluated in a symmetric equilibrium — actually call for some comments

$$
\begin{aligned}
& \lambda_{t}=v u_{1}-u_{1} n_{1} q_{1 t}-n_{2} u_{2} q_{2 t}-n_{1}\left(c_{1}-\mu_{1}\right) x_{t}^{\alpha_{1}} \\
& \lambda_{t}=v u_{2}-u_{2} n_{1} q_{1 t}-n_{2} u_{2} q_{2 t}-n_{2}\left(c_{2}-\mu_{2}\right) x_{t}^{\alpha_{2}} \\
& \lambda_{t}=\beta\left[\lambda_{t+1}\left(1+r\left(1-\frac{2}{k} x_{t+1}\right)\right)-\sum_{i=1}^{2}\left(\alpha_{i} q_{i t+1} n_{i}\left(c_{i}-\mu_{i}\right) x_{t+1}^{\alpha_{i}-1}\right)\right]
\end{aligned}
$$

for all $i$ and $t$ for which $q_{i t}>0$ and $x_{t+1}>0$. Parameter $\lambda_{t}$ represents the social current shadow value of an additional unit of stock along the optimal path. Observe that the first order conditions pertaining to the harvesting policy departs from the corresponding decisions in an equilibrium in at least two aspects. First, no matter the type of the firm we consider, firms have the same marginal valuation of an extra unit of fish, which dynamics is given by the last equation. Second, firms are not allowed to manipulate the price schedule, therefore eliminating the distorsion stemming from imperfect competition. This therefore fundamentally alters the harvesting policy of firms. Finally, the central planner chooses an intertemporal allocation of production that minimizes the distorsions stemming from coordination failures on the stock of fish. This is reflected by ( $i$ ) the fact that the marginal valuation of the stock is equated across firms $\left(\lambda_{1 t}=\lambda_{2 t}=\lambda_{t}\right)$ and (ii) the fact that the central planner acknowledges the total impact of postponing fishing on the total production cost (last part of the right hand side of the Euler equation). This can be simply illustrated looking at the steady state of the model. Indeed, for a given stock of fish $\bar{x}$ and two production levels $\left(q_{1}, q_{2}\right)=\left(\bar{q}_{1}, \bar{q}_{2}\right)$, it can be easily checked that the social shadow value of an additional unit of biomass, $\lambda$, is a linear combination of the private

\footnotetext{
${ }^{4}$ Note that this cost differs from the price paid by firms to obtain the technology.

${ }^{5} \Gamma$ is assumed to be increasing with $n$
} 
shadow values, $\lambda_{1}$ and $\lambda_{2}$

$$
\lambda=n_{1} \lambda_{1}+n_{2} \lambda_{2}
$$

Since $n_{i} \geqslant 1, i=1,2$, Ceteris Paribus, the steady state social marginal valuation of the stock of fish is greater than the private marginal valuation of the stock.

Technology adoption decisions are then taken by evaluating and comparing the value of the social optimum in the four possible cases we described in the previous sections.

It should be noted that the model is fundamentally non-linear and forward looking. It cannot be solved analytically. We therefore rely on a numerical evaluation of the model which requires to assign values to the structural parameters of the model.

\section{Parametrization}

The model is parameterized for the Northern Atlantic bluefin tuna fisheries using data collected by Barry and Kirkwood [1997] from the ICCAT for the year 1995. The two types of fishing firms we consider are long line (type 1 firms) and purse seine (type 2 firms) firms ${ }^{6}$ as they are representative of the tuna fishing industry. Indeed, the aggregate production of these two types of firms exceeds $75 \%$ of the total catch of the 1995 year. In the following LL refers to long line firms and PS refers to purse seine firms. The values of the structural parameters are reported in Table 1 .

The discount factor $\beta$ is set such that firms discount the future at a $4 \%$ annual rate, implying $\beta$ equals 0.96 . This is in accordance with other applied studies, using similar investment horizons, such as the US department of Commerce, National Marine and Fisheries Service (1995). The taste parameter $\bar{v}$ and the quality parameters $u_{1}$ and $u_{2}$ are not directly observable. We therefore assume that the economy was at its steady state in 1995 and set these parameters such that the model generates the observed catch of the 1995 year.

The number of each type of firms targeting bluefin tuna is relatively small, and we assume that $n_{1}=n_{2}=10$. We checked the robustness of our results against alternative numbers of firms and did not find any major change in the quantitative implications of the model to a change in either $n_{1}$ or $n_{2}$. The fishing technology, as specified in the model, requires some parameters to be set. Just like preferences, most of the parameters are not all directly observable. We therefore follow

\footnotetext{
${ }^{6}$ The purse seine is a huge net that is cast into the sea, gathering fish in its sweep. The fish is beaten with a stick so that the fish is stressed and damaged. The long line consists of cable to which smaller independent cables are attached at intervals of several meters. There is not much stress involved.
} 
the approach we used to set preference parameters and set the costs parameters, $c_{i}$, so as to match observed costs and prices in the tuna market for the year 1995. Data pertaining to prices and costs behavior are borrowed from the applied literature that has used a similar economic model (see Pintassilgo and Costa Duarte [2002] or Bjørndal, and Brasão [2004]). In the bluefin tuna fishery, LL and PS use advanced method of detection so that catches do not depend much upon the stock. Therefore, a low catch stock elasticity, $\alpha_{i}$, is often used in the literature. We follow this line and assume $\alpha_{1}=\alpha_{2}=-0.2$. Using this information together with the observed price levels and costs, $c_{1}$ and $c_{2}$ are set to the values reported in Table 1. Using satellite systems to support fishing allows firms to increase their catch per unit effort around $10 \%$. This implies that marginal production costs can decrease, $\delta_{i} / c_{i}$ by $10 \%$. This led to values for $\delta_{i}, i=1,2$, of, respectively, 44 and 23.

Table 1: Calibration

\begin{tabular}{lcrl}
\hline \hline Parameter & Mnemonic & Value & Units \\
\hline Preferences: & & & \\
Discount factor & $\beta$ & 0.96 & \\
Taste parameter & $\bar{v}$ & 80000 & \\
High quality parameter & $u_{1}$ & 0.0008 & \\
Low quality parameter & $u_{2}$ & 0.0005 & \\
& & & \\
Long line firms: & & & \\
price & $p_{1}$ & 17000 & USD/ton \\
number of firms & $n_{1}$ & 10 & \\
marginal cost & $c_{1}$ & 440 & USD/ton \\
cost reduction & $\delta_{1}$ & 44 & \\
catch stock elasticity & $\alpha 1$ & -0.2 & \\
& & & \\
Purse Seine firms: & & & \\
price & $p_{2}$ & 9000 & USD/ton \\
number of firms & $n_{2}$ & 10 & \\
marginal cost & $c_{2}$ & 223 & USD/ton \\
cost reduction & $\delta_{2}$ & 23 & \\
catch stock elasticity & $\alpha_{2}$ & -0.2 & \\
& & & \\
Resource stock: & & & \\
intrinsic growth rate & $r$ & 0.25 & \\
environmental carrying capacity & $k$ & 1200000 & tons \\
\hline \hline
\end{tabular}

The model of population dynamics borrows from Bjørndal et al. [2004] who propose a model of the evolution of the resource. According to their calculation, the total biomass should increase until 2040 and stabilise thereafter at a steady state level of about 1200000 MT. This led us to 
set $k=1200000$. Then, the intrinsic growth rate, $r$, is set so as to match the average growth rate over the period they consider.

Using this set of values, the model is then solved using a modified minimum weighted residuals method as advocated by Judd [1992] and Christiano and Fisher [2000].7]

\section{The results}

\subsection{The unregulated economy}

We first consider a benchmark situation in which none of the firms has access to the new technology and cannot therefore implement a cut in its costs. Figure 1 presents the harvesting decision rule of each type of firm and the associated present value. More precisely, it reports, for each level of the stock of fish, $x_{t}$, the equilibrium level of harvesting for each type of firm, $n_{i} q_{i t}$. Two main observations can be drawn from Figure 1. First, LL firms perform better than PS

Figure 1: Market equilibrium
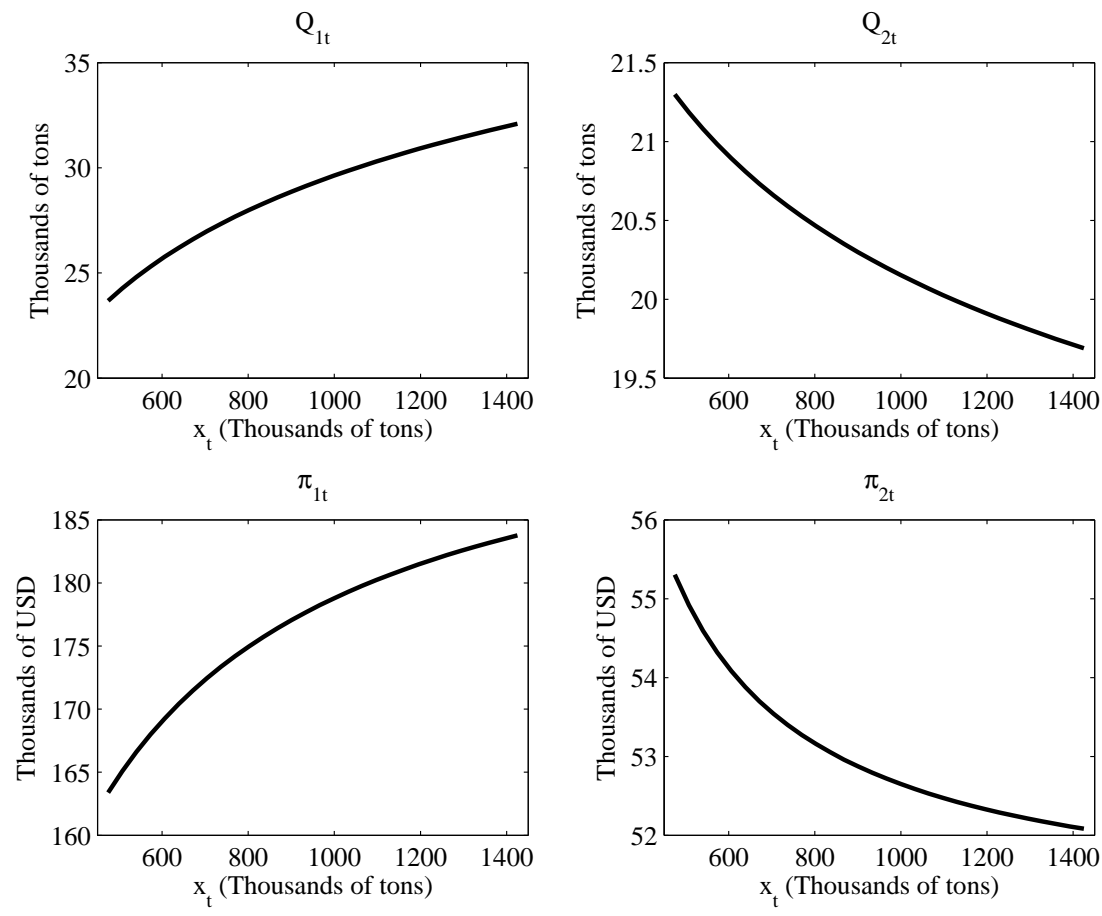

firms both in terms of production and in terms of present value. Second, LL firms benefit from an increase in the resource stock while PS firms experience both production and profit losses as the biomass increases. These two observations are actually accounted for by productivity differences. Indeed, as the resource increases, production costs decrease for both type of firm

\footnotetext{
${ }^{7}$ The reader is left to refer to Appendix $\overline{\mathrm{C}}$ for a detailed description of the method.
} 
$\left(\alpha_{i}<0\right)$ and therefore affect the degree of competition in the economy. Since LL firms are less productive than PS firms $\left(c_{1} \geqslant c_{2}\right)$, LL firms loose part of their oligopolistic power and become more competitive. They therefore have to produce more in order to maintain their profits. On the contrary, Ceteris Paribus, PS firms can charge a high price while lowering their harvesting level.

Figure 2 reports the comparison of optimal and equilibrium level of harvesting as well as the implied social surplus. Such a comparison is of great interest as it is well known that as soon

Figure 2: Optimal versus Equilibrium harvest
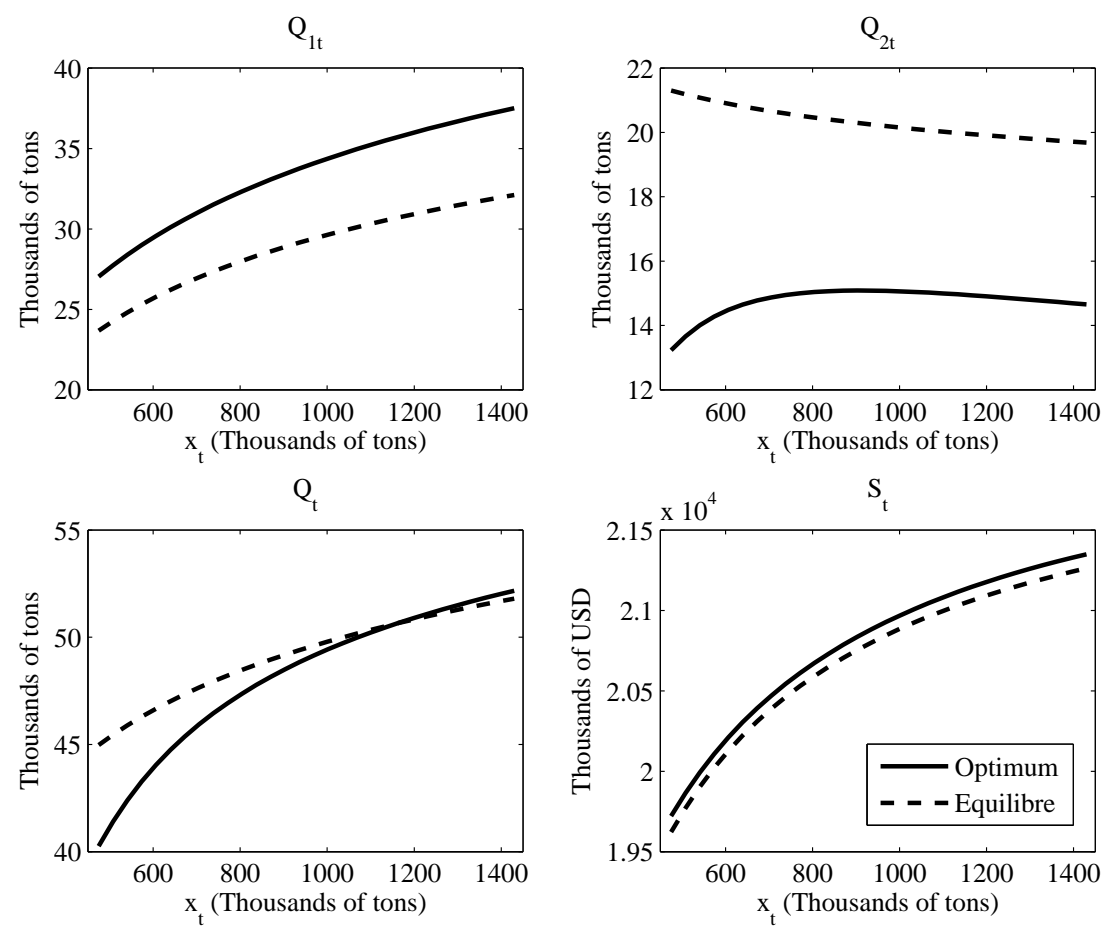

as several agents simultaneously exploit a productive common-property resource, the resulting externality generally leads to over-exploitation of the resource relative to the social optimum. This is so-called tragedy of the commons is important as it calls for a regulation of the equilibrium to bring the economy back to efficiency. In this competition model with quality differentiation, LL firms are found to under-produce whereas PS firms over-produce. The global effect is however ambiguous as over-production obtains for relatively low levels of the biomass and turns into under-production as the stock of fish is high. This latter under-exploitation of the resource has already been underlined and discussed by Dutta and Sundaram [1993]. In this model, this phenomenon arises because firms internalize the effect of their own production level on the price schedule. Indeed, when the resource is relatively abundant, firms limit their harvest so as to avoid the price cut - which would limit the rent they can extract from consumers - that would follow an increase in their production. 
Table 2 reports steady state harvests contingent on the technology adoption strategy of firms. In the table, $\mathrm{A}_{L L}$ (resp. $\AA_{L L}$ ) indicates that type $i$ firm adopts (resp. does not adopt) the new technology. The technology adoption clearly increases aggregate harvest but leaves the

Table 2: Steady state values

\begin{tabular}{ccccc}
\hline \hline & LL harvest & PS harvest & Aggregate harvest & Resource Stock \\
\hline$\left(A_{L L}, A_{P S}\right)$ & 29250 & 20220 & 49470 & 949979 \\
$\left(\mathrm{~A}_{L L}, \not_{P S}\right)$ & 35780 & 14280 & 50060 & 945927 \\
$\left(\mathbb{X}_{L L}, \mathrm{~A}_{P S}\right)$ & 26020 & 25740 & 51760 & 933976 \\
$\left(\mathrm{~A}_{L L}, \mathrm{~A}_{P S}\right)$ & 32550 & 19790 & 52340 & 929719 \\
\hline \hline
\end{tabular}

Note: All quantities are expressed in tons.

asymptotical behavior of the steady state fish stock essentially unaffected $8^{8}$ At the firm level, an increase in production depends on market competition. A single adoption makes the firm more competitive and increases its production level. When all firms adopt the new technology, LL firms increase their production but PS firms produce less than without the technology. Such an increase in aggregate harvest ought to lower social surplus. But, the adoption of the new technology has important consequences in terms of efficiency. Indeed, this induces a reallocation of harvests from less efficient toward more efficient firms. The over and under production results described above are therefore softened. This suggests a trade-off in the technology adoption decision, which we now investigate.

\subsubsection{Technology adoption in an equilibrium}

Figure 3 illustrates the effects of technology adoption on the payoffs of the firms in an equilibrium situation. The figure reports the gains in terms of net present value of adopting the new technology for each type of firm - i.e. the firms willingness to pay for the new technology for each possible value of the stock of fish. For instance, $\Delta_{L L}\left(\delta_{P S}\right)$ (resp. $\Delta_{L L}(0)$ ) plots the gains in terms of net present value for the long line firm (LL) of adopting the new technology when the Purse Seine has (resp. not) already adopted. As expected from the static analysis, the marginal returns of the cost reduction technology are larger when the other firm has not yet adopted the new technology. It is worth noting that the gains are decreasing functions of the stock of fish as the larger the stock the lower the need for a new technology since fish abundance lowers the cost of harvesting.

\footnotetext{
${ }^{8}$ Szidarovsky et al. [2002] perform a static comparative analysis of the steady state to a change in the harvest quantity. They find that an increase in the aggregate production either does not affect the asymptotic behavior of the steady state stock of fish or makes it more unstable.
} 
Figure 3: Cost reduction technology and increase in firms' profits
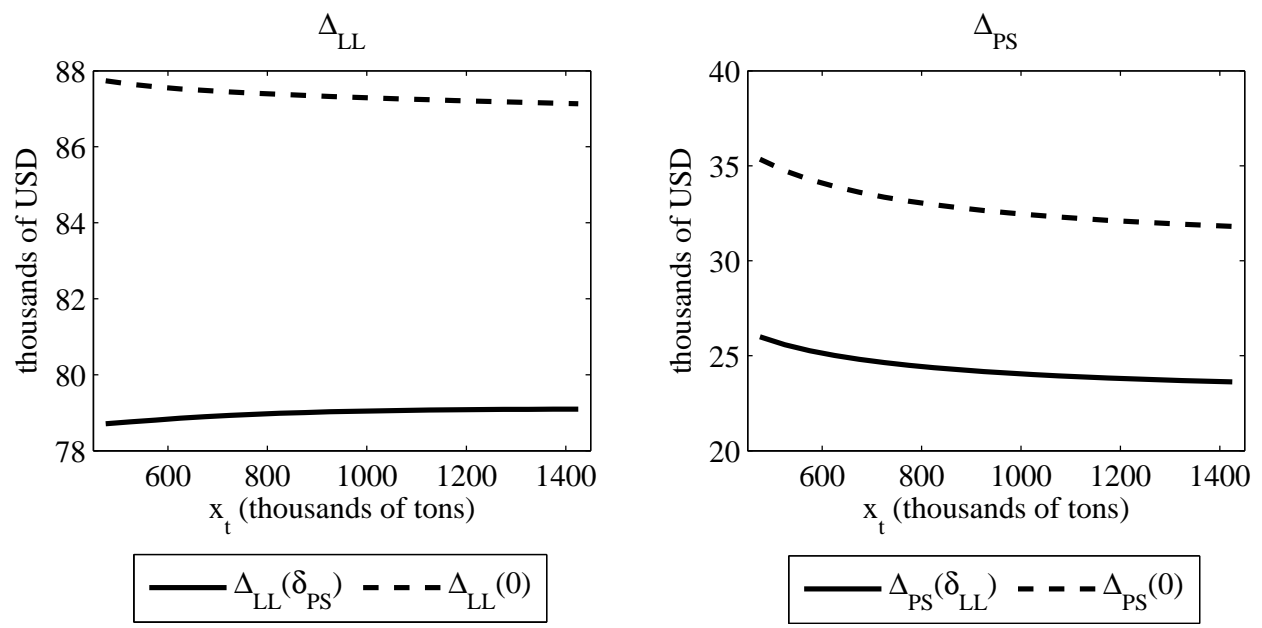

Strategies and payoffs in the steady state can be represented by the following gain matrix,

\begin{tabular}{c|c|c|}
\multicolumn{2}{c}{$\mathrm{A}_{P S}$} & \multicolumn{1}{c}{$\mathrm{X}_{P S}$} \\
\cline { 2 - 3 } $\mathrm{A}_{L L}$ & $\left(220943.6-T_{L L}, 50368-T_{P S}\right)$ & $\left(265756.3-T_{L L}, 26328.4\right)$ \\
\cline { 2 - 3 } $\mathcal{A}_{L L}$ & $\left(141898.5,85114.6-T_{P S}\right)$ & $(178455.5,52691.75)$ \\
\cline { 2 - 3 } & &
\end{tabular}

where the strategy of a LL firm is indicated in each row, while firms of type PS refer to each column. $\mathrm{A}_{L L}$ (resp. $\AA_{L L}$ ) indicates that type $i$ firm adopts (resp. does not adopt) the new technology. $T_{L L}$ and $T_{P S}$ both represent the adoption cost of the new technology for each type of firm. The increases in variable profits due to the technology adoption are given by thus

$$
\begin{array}{r}
\Delta_{L L}(0)=265756.30-178455.50=87300.80 \\
\Delta_{L L}\left(\delta_{P S}\right)=220943.60-141898.50=79045.10
\end{array}
$$

and

$$
\begin{aligned}
\Delta_{P S}(0) & =85114.60-52691.75=32422.85 \\
\Delta_{P S}\left(\delta_{L L}\right) & =50368.00-26328.40=24039.60
\end{aligned}
$$

This calculation indicates that LL firms are willing to pay $87300.80 \$$ to be equipped with the new system when PS firms do not possess it. Their willingness sharply drops to $79045.10 \$$ when the other type of firm is already equipped. Likewise, PS firms are willing to pay $32422.85 \$$ when LL firms are not equipped with the new technology while their valuation of the technology gain reduces to $24039.6 \$$ when LL firms are also equipped. It is worth noting that the technology is more valuable for LL firms than for PS firms as LL firms are less productive than PS firms $\left(c_{1} \geqslant c_{2}\right)$. 
Since the marginal valuation of the new technology is larger for LL than for PS firms, this raises the question of the optimality of serving all the market or only the LL firms. The answer to this question depends, to a large extent, on the possibility that technology costs differ among firms. Serving all the market with the new technology is optimal only when adoption is a dominant strategy for both types of firms. This actually occurs as long as the price of the new technology remains lower than $24039.6 \$$ for PS firms and $79045.1 \$$ for LL firms which generates a profit of $1030847 \$$. If the provider of the new technology cannot discriminate between firms, the maximum price for which it is optimal to serve all the market is therefore $24039.6 \$$ which yields a profit of $480792 \$$. When LL firms only are equipped, their willingness to pay is $87300.8 \$$. This yields a profit of $873008 \$$. Therefore, the last three experiments indicate that serving the all market is only optimal when the provider of the new technology can discriminate between firms.

\subsubsection{Socially Optimal Technology Adoption}

As in the equilibrium case, the technology adoption decision in the social optimum depends on the social value of the cost reduction technology. The next gain matrix reports the social surplus attained at the optimal harvest in the four possible cases

\begin{tabular}{c|c|c|}
\multicolumn{1}{c}{$\mathrm{A}_{P S}$} & $\mathcal{A}_{P S}$ \\
\cline { 2 - 3 } $\mathrm{A}_{L L}$ & $24002385-\Gamma\left(n_{L L}+n_{P S}\right)$ & $23650412-\Gamma\left(n_{L L}\right)$ \\
\cline { 2 - 3 }$A_{L L}$ & $21641277-\Gamma\left(n_{P S}\right)$ & 20945692 \\
\cline { 2 - 3 } & &
\end{tabular}

As can be seen from the matrix, the joint adoption of the technology yields an increase in the social surplus of $\left[24002385-\Gamma\left(n_{L L}+n_{P S}\right)\right]-20945692=3056693-\Gamma\left(n_{L L}+n_{P S}\right)$ relative to the use of the old technology. This therefore suggests that the joint adoption of the technology is preferred to a status quo as long as the total production cost of the technology does not exceed $3056693 \$$.

Since there are as many LL as PS firms, the adoption of the new technology by the sole LL firms is always preferred to the adoption by the sole PS firms $\left(23650412-\Gamma\left(n_{L L}\right) \geqslant 21641277-\Gamma\left(n_{P S}\right)\right)$.

The choice between a joint and a single adoption is driven by the level and the form of the technology production cost. Technology adoption by LL firms only yields an increase in the total surplus of $2704720-\Gamma\left(n_{L L}\right)$. The joint adoption increases the surplus by $351973-\Gamma\left(n_{L L}+\right.$ $\left.n_{P S}\right)+\Gamma\left(n_{L L}\right)$. Therefore, the joint adoption of the technology is preferred to a situation where LL firms only adopt it as long as the increase in the surplus (351973) exceeds the increase in the cost $\Gamma\left(n_{L L}+n_{P S}\right)+\Gamma\left(n_{L L}\right)$. Assuming that the market value of the technology exceeds its production cost, a joint adoption is preferable.

This analysis rests on a first best evaluation of the surplus. Social surplus is evaluated at the optimal level of harvest. It is however informative to evaluate the social value of the technology 
when harvesting levels are set to their equilibrium values. The gain matrix then takes the form

\begin{tabular}{c|c|c|}
\multicolumn{1}{c}{$\mathrm{A}_{P S}$} & $\mathcal{A}_{P S}$ \\
\cline { 2 - 3 } $\mathrm{A}_{L L}$ & $23875000-\Gamma\left(n_{L L}+n_{P S}\right)$ & $23450000-\Gamma\left(n_{L L}\right)$ \\
\cline { 2 - 3 } $\mathcal{A}_{L L}$ & $21611000-\Gamma\left(n_{P S}\right)$ & 20884000 \\
\cline { 2 - 3 } & &
\end{tabular}

A technology adoption by LL firms only yields an gain in the total surplus of $2566000-\Gamma\left(n_{L L}\right)$ which is smaller than in the first best analysis. But the joint adoption increases this surplus to a larger extent as it amounts to $425000-\Gamma\left(n_{L L}+n_{P S}\right)+\Gamma\left(n_{L L}\right)$. Again, assuming that the market value of the technology exceeds its production cost, joint adoption is preferable.

\subsection{Quotas and the market value of the technology}

Fishing is a highly regulated economic activity. In particular, international agreements impose some quotas on harvesting. It is then important to assess the impact of these quotas on the market valuation of the cost reducing technology. We therefore replicate the preceding analysis introducing quotas on one or both type of firms. More precisely, we consider three cases. In case 1, PS firms only are restricted by the quota, in case 2, LL firms only are restricted by the quota. In case 3 , both types of firm are restricted by the quotas. Figure 4 depicts the market equilibrium in case 2. As can be seen from the figure, imposing quotas on LL firms not only affect their production level but also the production level of PS firms. More precisely, as soon as LL firms hit the quotas, PS firms are able to capture a larger share of the market such that (i) they increase their production level in order to satisfy the demand side of the market and (ii) are able to increase their profit. This contrasts with the situation where no quotas are implemented as in this case PS firms profits are decreasing. Indeed, as soon as the quota is hit by the LL firm, only PS firms can indeed manipulate the price schedule. Therefore, only PS firms can fully benefit from any increase in the biomass. Their profit increase. Not to say that LL firms do not benefit from an increase in the stock of fish. Indeed, even if LL firms cannot increase their production, they benefit from the fact that the market price, as fixed by PS firms increase. Their profit do increase too.

Technology adoption is also potentially affected by the existence of quotas. This is investigated in Table 3 that reports the market value of the cost reducing technology for each case. We evaluate the profit that can be generated with a joint adoption and with a single adoption by LL firms. As can be seen from the table, the introduction of quotas increases the market value of the technology in case 2 and 3 where LL firms are limited in their production level. Indeed, LL firms being the less efficient firms $\left(c_{1} \geqslant c_{2}\right)$ they suffer much from the introduction of quotas and any device enhancing their productivity ought to be highly valued. Therefore, in these two cases, the firms' willingness to pay for the technology increases. Quotas can thus be used to 
Figure 4: Market equilibrium $-k_{1}=2500$
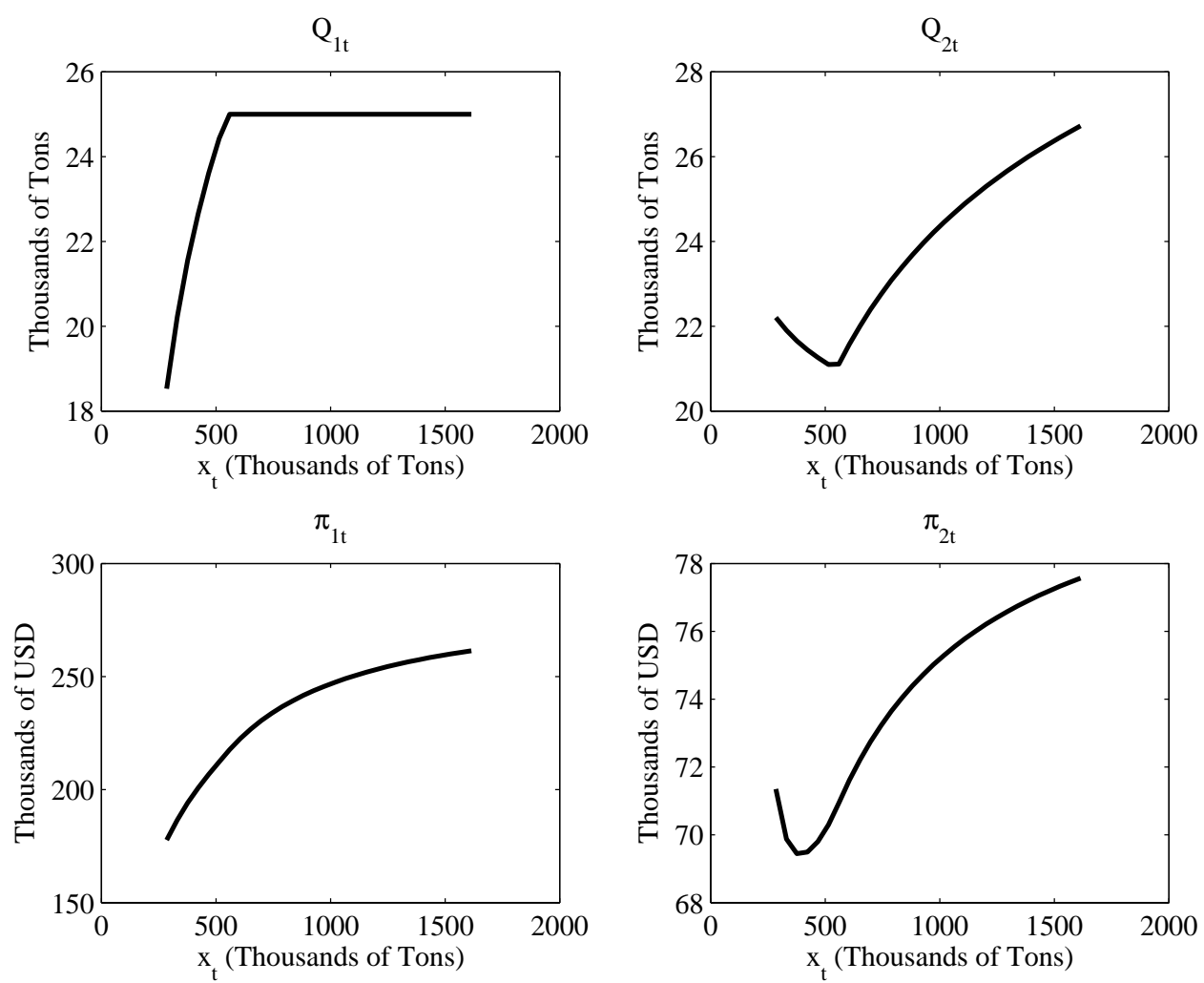

Table 3: Market value of the cost reduction technology (Thousands of USD)

\begin{tabular}{lcc}
\hline \hline & $\left(\mathrm{A}_{L L}, \mathrm{~A}_{P S}\right)$ & $\left(\mathrm{A}_{L L}, \AA_{P S}\right)$ \\
\hline No quotas & 1030 & 873 \\
Case $1\left(k_{2}=1500\right)$ & 933 & 492 \\
Case $2\left(k_{1}=2500\right)$ & 1908 & 1756 \\
Case $3\left(k_{1}=2500, k_{2}=1500\right)$ & 2282 & 1726 \\
\hline \hline
\end{tabular}


finance firms in their technology adoption.

\section{Conclusion}

This paper provides a framework to evaluate satellite systems to support fishing. Valuing this technology requires to evaluate the market equilibrium because marginal returns in the technology adoption are not constant.

We find that high quality firms value more the technology than low quality firms. This implies that serving all the market yields the highest profit if the price to access the technology can be different between firms. If price discrimination between firms is not possible, it is profitable to serve only highest quality firms. The socially optimal analysis yields similar results : the technology is more valuable for high quality firms than for low quality firms. If the technology cost is not too important, both types of firms should be equipped. Else, high quality firms only should adopt it. Finally, we show that individual quotas can be used to increase the value that both firms attach to the technology when high quality firms are restricted in their production levels.

\section{References}

Barry, C. and G. Kirkwood, Specifications of a Biological and Catch Prediction Model for Northern Bluefin Tuna, FAIR Project PL 96.1788, The management of High Seas Fisheries 1997.

Bester, H. and E. Petrakis, The Incentives for Cost Reduction in a Differentiated Industry, International Journal of Industrial Organization, 1994, 11 (4), 519-534.

Bjørndal, T., , and A. Brasão, The Northern Atlantic Bluefin Tuna Fisheries: Management and Policy Implications, Working Paper 69.0, FEEM 2004.

Christiano, L.J. and J.D.M. Fisher, Algorithms for Solving Dynamic Models with Occasionally Binding Constraints, Journal of Economic Dynamics and Control, 2000, 24 (8), 1179-1232.

Clark, C.W., Economically Optimal Policies for the Utilization of Biologically Renewable Resources, Mathematical Biosciences, 1971, 12 (3-4), 245-260.

and G.R. Munro, The Economics of Fishing and Modern Capital Theory: A simplified Approach, Journal of Environmental Economics and Management, 1975, 2 (2), 92-106. and J. Conrad, Natural Resource Economics. Notes and Problems, Cambridge University Press, 1987. 
Dutta, P. and R. Sundaram, The Tragedy of the Commons?, Economic Theory, 1993, 3, 413426.

Judd, K., Projection Methods for Solving Aggregate Growth Models, Journal of Economic Theory, 1992, 58, 410-452.

Levhari, D. and L.J. Mirman, The Great Fish War: An Example Using a Dynamic CournotNash Solution, The Bell Journal of Economics, 1980, 11 (1), 322-334.

Marcet, A. and G. Lorenzoni, The Parameterized Expectations Approach: Some Practical Issues, in M. Marimon and A. Scott, editors, Computational Methods for the Study of Dynamic Economies, Oxford: Oxford University Press, 1999.

Okugushi, K., Dynamic and Competitive Static Analysis of Imperfectly Competitive International Fishery, Journal of Economics, 2003, 80, 249-265.

Pintassilgo, P. and C. Costa Duarte, Optimal Management of the Northern Atlantic Bluefin Tuna, Marine Resource Economics, 2002, 17 (1), 47-67.

Sandal, L.K. and S.I. Steinshamn, Dynamic Cournot-competitive harvesting of a common pool resource, Journal of Economic Dynamics and Control, 2004, 28 (9), 1781-1799.

Szidarovsky, F., V. Ilieva, and K. Okuguchi, Entry and Merger in Commercial Fishing with Multiple Markets, Journal of Economics, 2002, 76 (3), 247-259. 


\section{- Appendix -}

\section{A Equilibrium conditions}

Recall that the profit maximization problem of firm $i$ is given by

$$
\begin{aligned}
\max _{q_{i t}} \Pi\left(\mu_{i}\right) & =\sum_{t=1}^{\infty} \beta^{t-1}\left(p_{i}\left(Q_{t}\right) q_{i t}-\left(c_{i}-\mu_{i}\right) q_{i t} x_{t}^{\alpha_{i}}\right) \\
\text { subject to } & \\
p_{1}\left(Q_{t}\right) & =\bar{v} u_{1}-u_{1} Q_{1 t}-u_{2} Q_{2 t} \\
p_{2}\left(Q_{t}\right) & =\bar{v} u_{2}-u_{2} Q_{1}-u_{2} Q_{2} \\
0 & \leq q_{i t} \\
q_{i t} & \leq k_{i} \\
x_{t+1} & =r x_{t}\left(1-\frac{x_{t}}{k}\right)+x_{t}-Q_{t} \\
0 & \leq x_{t+1}
\end{aligned}
$$

The set of optimality conditions is given by

$$
\begin{aligned}
\lambda_{1 t}-\nu_{1 t}+\zeta_{1 t} & =v u_{1}-u_{1}\left(1+n_{1}\right) q_{1 t}-n_{2} u_{2} q_{2 t}-\left(c_{1}-\mu_{1}\right) x_{t}^{\alpha_{1}} \\
\lambda_{2 t}-\nu_{2 t}+\zeta_{2 t} & =v u_{2}-u_{2} n_{1} q_{1 t}-\left(1+n_{2}\right) u_{2} q_{2 t}-\left(c_{2}-\mu_{2}\right) x_{t}^{\alpha_{2}} \\
\lambda_{i t}-\varphi_{t} & =\beta\left[\lambda_{i t+1}\left(1+r\left(1-\frac{2}{k} x_{t+1}\right)\right)-\alpha_{i} q_{i t+1}\left(c_{i}-\mu_{i}\right) x_{t+1}^{\alpha_{i}-1}\right] \\
\varphi_{t} x_{t+1} & =0 \\
\nu_{i t} q_{i t} & =0 \\
\zeta_{i t}\left(q_{i t}-k_{1}\right) & =0 \\
\varphi_{t} & \geqslant 0 \\
\nu_{i t} & \geqslant 0 \\
\zeta_{i t} & \geqslant 0
\end{aligned}
$$

for $i=\{1,2\}$.

\section{B Socially optimal conditions}

Recall that the socially optimal quantities are derived from.

$$
\begin{aligned}
\max _{q_{1 t}, q_{2 t}} & \sum_{t=1}^{\infty} \beta^{t-1}\left(S\left(n_{1} q_{1 t}+n_{2} q_{2 t}\right)-n_{1}\left(c_{1}-\mu_{1}\right) q_{1} x^{\alpha_{1}}+n_{2}\left(c_{2}-\mu_{2}\right) q_{2} x^{\alpha_{2}}\right. \\
\text { subject to } & \\
x_{t+1} & =r x_{t}\left(1-\frac{x_{t}}{k}\right)+x_{t}-Q_{t} \\
0 & \leq x_{t+1}
\end{aligned}
$$


The set of optimality conditions is given by

$$
\begin{aligned}
\lambda_{t} & =v u_{1}-u_{1} n_{1} q_{1 t}-n_{2} u_{2} q_{2 t}-n_{1}\left(c_{1}-\mu_{1}\right) x_{t}^{\alpha_{1}} \\
\lambda_{t} & =v u_{2}-u_{2} n_{1} q_{1 t}-n_{2} u_{2} q_{2 t}-n_{2}\left(c_{2}-\mu_{2}\right) x_{t}^{\alpha_{2}} \\
\lambda_{t}-\varphi_{t} & =\beta\left[\lambda_{t+1}\left(1+r\left(1-\frac{2}{k} x_{t+1}\right)\right)-\sum_{i=1}^{2}\left[\alpha_{i} q_{i t+1} n_{i}\left(c_{i}-\mu_{i}\right) x_{t+1}^{\alpha_{i}-1}\right]\right] \\
\varphi_{t} x_{t+1} & =0 \\
\varphi_{t} & \geqslant 0
\end{aligned}
$$

\section{Approximation Method}

Recall that the set of optimality conditions for the problem is given by

$$
\begin{aligned}
\lambda_{1 t}-\nu_{1 t}+\zeta_{1 t} & =v u_{1}-u_{1}\left(1+n_{1}\right) q_{1 t}-n_{2} u_{2} q_{2 t}-\left(c_{1}-\mu_{1}\right) x_{t}^{\alpha_{1}} \\
\lambda_{2 t}-\nu_{2 t}+\zeta_{2 t} & =v u_{2}-u_{2} n_{1} q_{1 t}-\left(1+n_{2}\right) u_{2} q_{2 t}-c_{2} x_{t}^{\alpha_{2}} \\
\lambda_{1 t}-\varphi_{t} & =\beta\left[\lambda_{1 t+1}\left(1+r\left(1-\frac{2}{k} x_{t+1}\right)\right)-\alpha_{1} q_{1 t+1}\left(c_{1}-\mu_{1}\right) x_{t+1}^{\alpha_{1}-1}\right] \\
\lambda_{2 t}-\varphi_{t} & =\beta\left[\lambda_{2 t+1}\left(1+r\left(1-\frac{2}{k} x_{t+1}\right)\right)-\alpha_{2} q_{2 t+1}\left(c_{2}-\mu_{2}\right) x_{t+1}^{\alpha_{2}-1}\right] \\
\varphi_{t} x_{t+1} & =0 \\
\nu_{1 t} q_{1 t} & =0 \\
\nu_{2 t} q_{2 t} & =0 \\
\zeta_{1 t}\left(q_{1 t}-k_{1}\right) & =0 \\
\zeta_{2 t}\left(q_{2 t}-k_{2}\right) & =0 \\
\varphi_{t} & \geqslant 0 \\
\nu_{1 t} & \geqslant 0 \\
\nu_{2 t} & \geqslant 0 \\
\zeta_{1 t} & \geqslant 0 \\
\zeta_{2 t} & \geqslant 0
\end{aligned}
$$

The algorithm is very close to the procedure suggested in Marcet and Lorenzoni [1999] and Christiano and Fisher [2000]. The basic idea of this approach is to approximate the expectation function - the right hand side of (C.3) - C.4 - of each player - rather than attempting to recover directly the decision rules - by a smooth function (a polynomial function). This amounts to replace C.3 - C.4 by

$$
\begin{aligned}
& \lambda_{1 t}-\varphi_{t}=\Phi_{1}\left(x_{t}, \Theta_{1}\right) \\
& \lambda_{2 t}-\varphi_{t}=\Phi_{2}\left(x_{t}, \Theta_{2}\right)
\end{aligned}
$$

where $\Phi_{1}\left(x_{t}, \Theta_{1}\right)$ and $\Phi_{2}\left(x_{t}, \Theta_{2}\right)$ approximate the quantities

$$
\beta\left[\lambda_{1 t+1}\left(1+r\left(1-\frac{2}{k} x_{t+1}\right)\right)-\alpha_{1} q_{1 t+1}\left(c_{1}-\mu_{1}\right) x_{t+1}^{\alpha_{1}-1}\right]
$$

and

$$
\beta\left[\lambda_{2 t+1}\left(1+r\left(1-\frac{2}{k} x_{t+1}\right)\right)-\alpha_{2} q_{2 t+1}\left(c_{2}-\mu_{2}\right) x_{t+1}^{\alpha_{2}-1}\right]
$$

respectively. 
The two approximating functions are given by linear combinations of Chebychev polynomials

$$
\Phi_{\ell}\left(x_{t} ; \Theta_{\ell}\right) \equiv \sum_{j=0}^{n} \theta_{\ell, j} T_{j}\left(\Psi\left(x_{t}\right)\right) \text { for } \ell=1,2
$$

where $T_{j}(\cdot)$ is the Chebychev polynomial of order $j$. This class of polynomial possesses a discrete orthogonality property which has proven extremely efficient and useful in approximation theory. Since Chebychev polynomials are defined over $[-1 ; 1]$, while $x_{t}$ is not, $x_{t}$ is transformed by means of function

$$
\Psi(x)=2 \frac{x-\underline{x}}{\bar{x}-\underline{x}}-1
$$

which maps $[\underline{x} ; \bar{x}]$ into $[-1 ; 1]$.

The parameters of the approximating functions, $\Theta_{1}$ and $\Theta_{2}$, are then revealed by imposing identifying restrictions dictated by economic theory. More precisely, they are determined by imposing an orthogonality condition on the residuals of the Euler equations.

Note that in the sequel a' will denote a variables evaluated in the next period $(t+1)$.

The algorithm then works as follows.

1. Choose an order of approximation $n$, compute the $m>n$ roots of the Chebychev polynomial of order $m_{x}$ as

$$
z_{i}=\cos \left(\frac{(2 i-1) \pi}{2(n+1)}\right) \text { for } i=1, \ldots, m
$$

2. Compute the matrix $\mathscr{T}(z)$

$$
\mathscr{T}(z)=\left(\begin{array}{ccc}
T_{0}\left(z_{1}\right) & \cdots & T_{0}\left(z_{m}\right) \\
\vdots & \ddots & \vdots \\
T_{n}\left(z_{1}\right) & \cdots & T_{n}\left(z_{m}\right)
\end{array}\right)
$$

3. Compute $x_{i}$ as

$$
x_{i}=\log (\underline{x})+\left(z_{i}+1\right) \frac{\log (\bar{x})-\log (\underline{x}))}{2} \text { for } i=1, \ldots, m
$$

to map $[-1 ; 1]$ into $[\underline{x} ; \bar{x}]$.

4. Compute the approximating expectation function of each player, $\ell$, at each node $x_{i}, i=1, \ldots, m$

$$
\Phi_{\ell}\left(x_{i} ; \Theta_{\ell}\right) \equiv \sum_{j=0}^{n} \theta_{\ell, j} T_{j}\left(z_{i}\right) \text { for } \ell=1,2
$$

5. Using this expectation function, obtain quantities fished by each player in an unconstrained equilibrium for each value of the stock, $x_{i}$. In such a situation, we have $0<q_{1 i}<k_{1}, 0<q_{2 i}<k_{2}$, and $x_{i}^{\prime}>0$. This implies that $\nu_{1 i}=\nu_{2 i}=\zeta_{1 i}=\zeta_{2 i}=\varphi_{i}=0$. A direct consequence of this is that $\lambda_{1 i}$ and $\lambda_{2 i}$ are simply given by

$$
\begin{aligned}
& \lambda_{1 i}=\Phi_{1}\left(x_{i}, \Theta_{1}\right) \\
& \lambda_{2 i}=\Phi_{2}\left(x_{i}, \Theta_{2}\right)
\end{aligned}
$$

and $q_{1 i} \equiv Q_{1}\left(x_{i}, \Theta_{1}, \Theta_{2}\right)$ and $q_{2 i}=Q_{2}\left(x_{i}, \Theta_{1}, \Theta_{2}\right)$ are obtained by solving the simple linear system

$$
\begin{aligned}
& u_{1}\left(1+n_{1}\right) q_{1 i}+n_{2} u_{2} q_{2 i}=v u_{1}-\lambda_{1 i}-\left(c_{1}-\mu_{1}\right) x_{i}^{\alpha_{1}} \\
& u_{2} n_{1} q_{1 i}-\left(1+n_{2}\right) u_{2} q_{2 i}=v u_{2}-\lambda_{2 i}-\left(c_{2}-\mu_{2}\right) x_{i}^{\alpha_{2}}
\end{aligned}
$$

Then the unconstrained future value of tuna stock, $x_{i}^{\prime} \equiv\left(x_{i}, \Theta_{1}, \Theta_{2}\right)$ is given by

$$
x_{i}^{\prime}=r x_{i}\left(1-\frac{x_{i}}{k}\right)+x_{i}-n_{1} q_{1 i}-n_{2} q_{2 i}
$$


6. Check whether any constraint, on $q_{1 i}, q_{2 i}$ or $x_{i}^{\prime}$ is binding for each $x_{i}, i=1, \ldots, n$

- If the constraint is not binding then keep the computed values for $q_{1 i}, q_{2 i}, x_{i}^{\prime}$, and set $\nu_{1 i}=$ $\nu_{2 i}=\zeta_{1 i}=\zeta_{2 i}=\varphi_{i}=0$

- If any constraint is binding, then adapt the equilibrium values accordingly 9

At this step we have equilibrium values for each quantity and price in the current period. We also have next period tuna stock. We are then in a position to compute the next period values.

7. For each value $x_{i}^{\prime}=X\left(x_{i}, \Theta_{1}, \Theta_{2}\right)$ apply the transformation

$$
\Psi(x)=2 \frac{x-\underline{x}}{\bar{x}-\underline{x}}-1
$$

which maps $[\underline{x} ; \bar{x}]$ into $[-1 ; 1]$. Then build the matrix

$$
\mathscr{T}^{\prime}(x)=\left(\begin{array}{ccc}
T_{0}\left(\Psi\left(x_{1}\right)\right) & \cdots & T_{0}\left(\Psi\left(x_{m}\right)\right) \\
\vdots & \ddots & \vdots \\
T_{n}\left(\Psi\left(x_{1}\right)\right) & \cdots & T_{n}\left(\Psi\left(x_{m}\right)\right)
\end{array}\right)
$$

8. Compute next period approximating expectation function of each player, $\ell$, at each node $x_{i}^{\prime}, i=$ $1, \ldots, m$

$$
\Phi_{\ell}\left(x_{i}^{\prime} ; \theta\right) \equiv \sum_{j=0}^{n} \theta_{\ell, j} T_{j}\left(\Psi\left(x_{i}^{\prime}\right)\right) \text { for } \ell=1,2
$$

and obtain next period equilibrium values as obtained in steps 5 and 6 .

9. Evaluate the residuals $R_{1}\left(x_{i}, \Theta_{1}, \Theta_{2}\right)$ and $R_{2}\left(x_{i}, \Theta_{1}, \Theta_{2}\right)$ obtained as

$$
\begin{aligned}
& R_{1}\left(x_{i}, \Theta_{1}, \Theta_{2}\right)=\beta\left[\lambda_{1 i}^{\prime}\left(1+r\left(1-\frac{2}{k} x_{i}^{\prime}\right)\right)-\alpha_{1} q_{1 i}^{\prime}\left(c_{1}-\mu_{1}\right) x_{i}^{\prime \alpha_{1}-1}\right]-\Phi_{1}\left(x_{i} ; \Theta_{1}\right) \\
& R_{2}\left(x_{i}, \Theta_{1}, \Theta_{2}\right)=\beta\left[\lambda_{2 i}^{\prime}\left(1+r\left(1-\frac{2}{k} x_{i}^{\prime}\right)\right)-\alpha_{2} q_{2 i}^{\prime}\left(c_{2}-\mu_{2}\right) x_{i}^{\prime \alpha_{2}-1}\right]-\Phi_{2}\left(x_{i} ; \Theta_{2}\right)
\end{aligned}
$$

for each $i=1, \ldots, m$.

10. Compute the inner products

$$
\begin{aligned}
& \mathscr{T}(z) R_{1}\left(x, \Theta_{1}, \Theta_{2}\right)=0 \\
& \mathscr{T}(z) R_{2}\left(x, \Theta_{1}, \Theta_{2}\right)=0
\end{aligned}
$$

11. if all inner products are close enough to zero then stop, else update $\Theta_{1}$ and $\Theta_{2}$ and go back to 4 .

Note that, as in the standard PEA algorithm, we treat $\nu_{i t}, \zeta_{i t}$ and $\varphi_{t}$ as technical variables which are just used to compute the residuals. We therefore do not need to compute explicitly its interpolating function.

From a practical point of view, we use 30th order Chebychev polynomials and 1000 nodes. These values are actually very high but allow us to achieve high accuracy of the approximation over the support $[(1-\Delta) \bar{x} ;(1+\Delta) \bar{x}]$ where $\bar{x}$ is the steady state of the model and $\Delta=0.5$.

\footnotetext{
${ }^{9}$ This is described in appendix $\mathrm{D}$
} 


\section{Constrained Equilibrium}

This section presents the possible equilibria that may occur, given the constraints imposed on the problem.

Case 1: $0<q_{1 t}<k_{1}, 0<q_{2 t}<k_{2}$, and $x_{t+1}>0$. This implies that $\nu_{1 t}=\nu_{2 t}=\zeta_{1 t}=\zeta_{2 t}=\varphi_{t}=0$ and

$$
\begin{aligned}
& \lambda_{1 t}=\Phi_{1}\left(x_{t}, \Theta_{1}\right) \\
& \lambda_{2 t}=\Phi_{2}\left(x_{t}, \Theta_{2}\right)
\end{aligned}
$$

Then $q_{1 i} \equiv Q_{1}\left(x_{i}, \Theta_{1}, \Theta_{2}\right)$ and $q_{2 i}=Q_{2}\left(x_{i}, \Theta_{1}, \Theta_{2}\right)$ are obtained by solving the simple linear system

$$
\begin{aligned}
& u_{1}\left(1+n_{1}\right) q_{1 i}+n_{2} u_{2} q_{2 i}=v u_{1}-\lambda_{1 i}-\left(c_{1}-\mu_{1}\right) x_{i}^{\alpha_{1}} \\
& u_{2} n_{1} q_{1 i}-\left(1+n_{2}\right) u_{2} q_{2 i}=v u_{2}-\lambda_{2 i}-\left(c_{2}-\mu_{2}\right) x_{i}^{\alpha_{2}}
\end{aligned}
$$

Case 2: Given the unconstrained equilibrium: $0<q_{1 t}<k_{1}, 0<q_{2 t}<k_{2}$, and $x_{t+1}<0$. This implies that $\nu_{1 t}=\nu_{2 t}=\zeta_{1 t}=\zeta_{2 t}=0$ and $\varphi_{t}>0$. Then we set

$$
x_{t+1}=0
$$

The other variables are a solution of the following system

$$
\left\{\begin{aligned}
\lambda_{1 t}-\nu_{1 t}+\zeta_{1 t} & =v u_{1}-u_{1}\left(1+n_{1}\right) q_{1 t}-n_{2} u_{2} q_{2 t}-\left(c_{1}-\mu_{1}\right) x_{t}^{\alpha_{1}} \\
n_{1} q_{1 t}+n_{2} q_{2 t} & =r x_{t}\left(1-\frac{x_{t}}{k}\right)+x_{t} \\
\lambda_{2 t}-\nu_{2 t}+\zeta_{2 t} & =v u_{2}-u_{2} n_{1} q_{1 t}-\left(1+n_{2}\right) u_{2} q_{2 t}-\left(c_{2}-\mu_{2}\right) x_{t}^{\alpha_{2}} \\
\lambda_{1 t}-\varphi_{t} & =\Phi_{1}\left(x_{t}, \Theta_{1}\right) \\
\lambda_{2 t}-\varphi_{t} & =\Phi_{2}\left(x_{t}, \Theta_{2}\right)
\end{aligned}\right.
$$

Case 3: Given the unconstrained equilibrium: $q_{1 t}<0,0<q_{2 t}<k_{2}$, and $x_{t+1}>0$. This implies that $\nu_{1 t}>0, \nu_{2 t}=\zeta_{1 t}=\zeta_{2 t}=\varphi_{t}=0$. Then we set

$$
q_{1 t}=0 \text { and } q_{2 t}=\frac{v u_{2}-\left(c_{2}-\mu_{2}\right) x_{t}^{\alpha_{2}}-\lambda_{2 t}}{u_{2}\left(1+n_{2}\right)}
$$

with

$$
\begin{aligned}
& \lambda_{1 t}=\Phi_{1}\left(x_{t}, \Theta_{1}\right) \\
& \lambda_{2 t}=\Phi_{2}\left(x_{t}, \Theta_{2}\right)
\end{aligned}
$$

Case 4: Given the unconstrained equilibrium: $q_{1 t}<0,0<q_{2 t}<k_{2}$, and $x_{t+1}<0$. This implies that $\nu_{1 t}>0, \nu_{2 t}=\zeta_{1 t}=\zeta_{2 t}=0$ and $\varphi_{t}>0$. Then we set

$$
q_{1 t}=0 \text { and } q_{2 t}=\frac{1}{n_{2}}\left(r x_{t}\left(1-\frac{x_{t}}{k}\right)+x_{t}\right)
$$

and

$$
\begin{aligned}
\lambda_{2 t} & =v u_{2}-\left(1+n_{2}\right) u_{2} q_{2 t}-\left(c_{2}-\mu_{2}\right) x_{t}^{\alpha_{2}} \\
\varphi_{t} & =\lambda_{2 t}-\Phi_{2}\left(x_{t}, \Theta_{2}\right) \\
\lambda_{1 t} & =\varphi_{t}+\Phi_{1}\left(x_{t}, \Theta_{1}\right)
\end{aligned}
$$

Case 5: Given the unconstrained equilibrium: $q_{1 t}<0, q_{2 t}<0$, and $x_{t+1}>0$. This implies that $\nu_{1 t}>0$, $\nu_{2 t}>0, \zeta_{1 t}=\zeta_{2 t}=\varphi_{t}=0$. Then we set

$$
q_{1 t}=q_{2 t}=0 \text { and } x_{t+1}=r x_{t}\left(1-\frac{x_{t}}{k}\right)+x_{t}
$$

and

$$
\begin{aligned}
& \lambda_{1 t}=\Phi_{1}\left(x_{t}, \Theta_{1}\right) \\
& \lambda_{2 t}=\Phi_{2}\left(x_{t}, \Theta_{2}\right)
\end{aligned}
$$


Case 6: Given the unconstrained equilibrium: $q_{1 t}<0, q_{2 t}<0$, and $x_{t+1}<0$. This is clearly not an equilibrium

Case 7: Given the unconstrained equilibrium: $q_{1 t}<0, q_{2 t}>k_{2}$, and $x_{t+1}>0$. This implies that $\nu_{1 t}>0$, $\zeta_{2 t}>0, \zeta_{1 t}=\nu_{2 t}=\varphi_{t}=0$. Then we set

$$
q_{1 t}=0, q_{2 t}=k_{2} \text { and } x_{t+1}=r x_{t}\left(1-\frac{x_{t}}{k}\right)+x_{t}-n_{2} k_{2}
$$

and

$$
\begin{aligned}
\lambda_{1 t} & =\Phi_{1}\left(x_{t}, \Theta_{1}\right) \\
\lambda_{2 t} & =\Phi_{2}\left(x_{t}, \Theta_{2}\right)
\end{aligned}
$$

Case 8: Given the unconstrained equilibrium: $q_{1 t}<0, q_{2 t}>k_{2}$, and $x_{t+1}<0$. This case is equivalent to case 4 .

Case 9: Given the unconstrained equilibrium: $q_{1 t}>k_{1}, 0<q_{2 t}<k_{2}$, and $x_{t+1}>0$. This implies that $\zeta_{1 t}>0, \nu_{1 t}=\nu_{2 t}=\zeta_{2 t}=\varphi_{t}=0$. Then we set

$$
q_{1 t}=k_{1}, q_{2 t}=\frac{v u_{2}-n_{1} u_{2} k_{1}-\left(c_{2}-\mu_{2}\right) x_{t}^{\alpha_{2}}-\lambda_{2 t}}{u_{2}\left(1+n_{2}\right)} \text { and } x_{t+1}=r x_{t}\left(1-\frac{x_{t}}{k}\right)+x_{t}-n_{1} k_{1}-n_{2} q_{2 t}
$$

and

$$
\begin{aligned}
& \lambda_{1 t}=\Phi_{1}\left(x_{t}, \Theta_{1}\right) \\
& \lambda_{2 t}=\Phi_{2}\left(x_{t}, \Theta_{2}\right)
\end{aligned}
$$

Case 10: Given the unconstrained equilibrium: $q_{1 t}>k_{1}, 0<q_{2 t}<k_{2}$, and $x_{t+1}<0$. This implies that $\zeta_{1 t}>0, \nu_{1 t}=\nu_{2 t}=\zeta_{2 t}=0$ and $\varphi_{t}>0$. Then we set

$$
q_{1 t}=k_{1} \text { and } x_{t+1}=0
$$

We have

$$
\begin{aligned}
q_{2 t} & =\frac{1}{k_{2}}\left(r x_{t}\left(1-\frac{x_{t}}{k}\right)+x_{t}-n_{1} k_{1}\right) \lambda_{2 t}=v u_{2}-n_{1} u_{2} k_{1}-\left(1+n_{2}\right) u_{2} q_{2 t}-\left(c_{2}-\mu_{2}\right) x_{t}^{\alpha_{2}} \\
\varphi_{t} & =\lambda_{2 t}-\Phi_{2}\left(x_{t}, \Theta_{2}\right) \\
\lambda_{1 t} & =\varphi_{t}+\Phi_{1}\left(x_{t}, \Theta_{1}\right)
\end{aligned}
$$

Case 11: Given the unconstrained equilibrium: $q_{1 t}>k_{1}, q_{2 t}>k_{2}$, and $x_{t+1}>0$. This implies that $\zeta_{1 t}>0$, $\zeta_{2 t}>0, \nu_{1 t}=\nu_{2 t}=\varphi_{t}=0$. Then we set

$$
q_{1 t}=k_{1}, q_{2 t}=k_{2} \text { and } x_{t+1}=r x_{t}\left(1-\frac{x_{t}}{k}\right)+x_{t}-n_{1} k_{1}-n_{2} k_{2}
$$

We have

$$
\begin{aligned}
& \lambda_{1 t}=\Phi_{1}\left(x_{t}, \Theta_{1}\right) \\
& \lambda_{2 t}=\Phi_{2}\left(x_{t}, \Theta_{2}\right)
\end{aligned}
$$

Case 12: Given the unconstrained equilibrium: $q_{1 t}>k_{1}, q_{2 t}>k_{2}$, and $x_{t+1}<0$. This case is identical to case 2 .

Case 13: Given the unconstrained equilibrium: $0<q_{1 t}<k_{1}, q_{2 t}<0$, and $x_{t+1}>0$. This implies that $\nu_{2 t}>0$, and $\nu_{1 t}=\zeta_{2 t}=\zeta_{2 t}=\varphi_{t}=0$. Then we set

$$
q_{1 t}=\frac{v u_{1}-\left(c_{1}-\mu_{1}\right) x_{t}^{\alpha_{1}}-\lambda_{1 t}}{u_{1}\left(1+n_{1}\right)}, q_{2 t}=0 \text { and } x_{t+1}=r x_{t}\left(1-\frac{x_{t}}{k}\right)+x_{t}-n_{1} q_{1 t}
$$

We have

$$
\begin{aligned}
\lambda_{1 t} & =\Phi_{1}\left(x_{t}, \Theta_{1}\right) \\
\lambda_{2 t} & =\Phi_{2}\left(x_{t}, \Theta_{2}\right)
\end{aligned}
$$


Case 14: Given the unconstrained equilibrium: $0<q_{1 t}<k_{1}, q_{2 t}<0$, and $x_{t+1}<0$. This implies that $\nu_{2 t}>0, \nu_{1 t}=\zeta_{2 t}=\zeta_{2 t}=0$ and $\varphi_{t}>0$. Then we set

$$
q_{1 t}=\frac{1}{n_{1}}\left(r x_{t}\left(1-\frac{x_{t}}{k}\right)+x_{t}\right), q_{2 t}=0 \text { and } x_{t+1}=0
$$

We have

$$
\begin{aligned}
\lambda_{1 t} & =v u_{1}-\left(1+n_{1}\right) u_{1} q_{1 t}-\left(c_{1}-\mu_{1}\right) x_{t}^{\alpha_{1}} \\
\lambda_{2 t} & =\Phi_{2}\left(x_{t}, \Theta_{2}\right) \\
\varphi_{t} & =\lambda_{1 t}+\Phi_{1}\left(x_{t}, \Theta_{1}\right)
\end{aligned}
$$

Case 15: Given the unconstrained equilibrium: $q_{1 t}>k_{1}, q_{2 t}<0$, and $x_{t+1}>0$. This implies that $\zeta_{1 t}>0$, $\nu_{2 t}>0, \nu_{1 t}=\zeta_{2 t}=\varphi_{t}=0$. Then we set

$$
q_{1 t}=k_{1}, q_{2 t}=0 \text { and } x_{t+1}=r x_{t}\left(1-\frac{x_{t}}{k}\right)+x_{t}-n_{1} k_{1}
$$

We have

$$
\begin{aligned}
& \lambda_{1 t}=\Phi_{1}\left(x_{t}, \Theta_{1}\right) \\
& \lambda_{2 t}=\Phi_{2}\left(x_{t}, \Theta_{2}\right)
\end{aligned}
$$

Case 16: Given the unconstrained equilibrium: $q_{1 t}>k_{1}, q_{2 t}<0$, and $x_{t+1}<0$. This case is identical to case 14 .

Case 17: Given the unconstrained equilibrium: $0<q_{1 t}<k_{1}, q_{2 t}>k_{2}$, and $x_{t+1}>0$. This implies that $\zeta_{2 t}>0, \nu_{1 t}=\zeta_{1 t}=\nu_{2 t}=\varphi_{t}=0$. Then we set

$$
q_{1 t}=\frac{v u_{1}-n_{2} u_{2} k_{2}-\left(c_{1}-\mu_{1}\right) x_{t}^{\alpha_{1}}-\lambda_{1 t}}{u_{1}\left(1+n_{1}\right)}, q_{2 t}=k_{2} \text { and } x_{t+1}=r x_{t}\left(1-\frac{x_{t}}{k}\right)+x_{t}-n_{1} q_{1 t}-n_{2} k_{2}
$$

We have

$$
\begin{aligned}
\lambda_{1 t} & =\Phi_{1}\left(x_{t}, \Theta_{1}\right) \\
\lambda_{2 t} & =\Phi_{2}\left(x_{t}, \Theta_{2}\right)
\end{aligned}
$$

Case 18: Given the unconstrained equilibrium: $0<q_{1 t}<k_{1}, q_{2 t}>k_{2}$, and $x_{t+1}<0$. This implies that $\zeta_{2 t}>0, \nu_{1 t}=\zeta_{1 t}=\nu_{2 t}=0$ and $\varphi_{t}>0$. Then we set

$$
q_{1 t}=\frac{1}{n_{1}}\left(r x_{t}\left(1-\frac{x_{t}}{k}\right)+x_{t}-n_{2} k_{2}\right), q_{2 t}=k_{2} \text { and } x_{t+1}=0
$$

We have

$$
\begin{aligned}
& \lambda_{1 t}=v u_{1}-u_{1}\left(1+n_{1}\right) q_{1 t}-n_{2} u_{2} k_{2}-\left(c_{1}-\mu_{1}\right) x_{t}^{\alpha_{1}} \\
& \lambda_{2 t}=\Phi_{2}\left(x_{t}, \Theta_{2}\right) \\
& \varphi_{t}=\lambda_{1 t}+\Phi_{1}\left(x_{t}, \Theta_{1}\right)
\end{aligned}
$$

